\title{
5. Face, Frame, Fragment: Refiguring Space in Found-Footage Cinema
}

\author{
Allan Cameron
}

\begin{abstract}
In experimental 'found footage' films by Peter Tscherkassky, Nicolas Provost, and Gregg Biermann, the relationship between the cinematic face and frame is refigured. Using techniques of superimposition, distortion, collage, and montage to manipulate familiar screen faces and settings, these films invite us to reinhabit familiar cinematic worlds while reframing and rearticulating their spatial dimensions. In doing so, they concentrate not only on the face as visible expressive element but also on the spatiotemporal gesture of facing. The face thus becomes a pivot around which to orient explorations of surface and depth, figuration and fragmentation. By teasing apart and rearranging the relationship between cinematic faces and spaces, these works point cinema in new directions.
\end{abstract}

Keywords: Faciality, spatiality, experimental film, remix, collage, montage

In narrative cinema, the human face and the film frame are intimately connected in ways that might seem obvious but are, for that very reason, easy to overlook. Arguably, one underwrites the value of the other. Whereas landscapes and streets are all too readily interpretable as 'empty spaces', the presence of the face provides assurance that we are looking at a potential object of dramatic interest - the face occupies the frame, in other words, and authorizes it in the process. Similarly, the frame vouches for the significance of the face, scrutinizing it intently in the close-up, or, by placing it strategically in wider compositions, underlining its importance as

Sæther, S.Ø. and S.T. Bull (eds.), Screen Space Reconfigured. Amsterdam: Amsterdam University Press, 2020 DOI 10.5117/9789089649928_CHO5 
a narrative, spatial, and affective anchor point. ${ }^{1}$ Furthermore, as the bearer of the 'look' in two senses (as the site of the visual organs and the primary zone of affective expression), the face collaborates with the frame in the articulation of dramatic space. In a number of contemporary experimental 'found footage' films, however, this intimate connection between face and frame forms the basis for an investigation and renegotiation of screen space, as fragments of narrative cinema are disarticulated, superimposed, distorted, and juxtaposed.

Approaching the face as an identifiable figure that can be distinguished from its ground, these films also use a number of techniques-notably collage and montage - to disrupt or overturn the figuration of the face. For the purpose of this discussion, I consider montage as a diachronic approach that suggests conceptual and/or spatiotemporal connections in time, while collage is a synchronic, additive approach that emphasizes spatial juxtaposition. ${ }^{2}$ Some of these films rely primarily upon montage, while others create synchronic collage effects by producing visible or invisible seams within the frame itself, emphasizing visual boundaries and fragments. In each case, as fragments of the cinematic origin text are modified, layered, or reordered, figure and ground enter into a push-and-pull relationship -in some instances, the spatial environment subsumes the face; in others, the face is cut free from its surroundings. Collectively, these works use faces as a pivot around which to orient explorations of surface and depth, figuration and fragmentation. In doing so, they concentrate not only on the face as visible expressive element but also on the spatiotemporal gesture of facing. ${ }^{3}$

1 Film scholarship has tended to view the facial close-up, in particular, as integral to narrative cinema: from Béla Balázs' early theorization of cinema's 'mighty visual anthropomorphism' (in Balázs, Theory of the Film, p. 6o) to Deleuze's assertion that 'The affection-image is the close-up, and the close-up is the face' (in Deleuze, Cinema I, p. 89). As Mary Ann Doane puts it, 'The close-up, together with an editing that penetrates space and is at least partially rationalized by that close-up, seems to mark the moment of the very emergence of film as a discourse, as an art' (in Doane, 'The Close-Up', p. 91).

2 This difference is not insisted upon by all writers on film. William Wees, in his influential account of found-footage cinema, sees 'montage' and 'collage' as functionally equivalent: 'As far as I am concerned, either term will do, so long as it is understood to mean the juxtaposition of pre-existing elements extracted from their original contexts, diverted [...] from their original, intended uses, and thereby made to yield previously unrecognized significance' (Wees, Recycled Images, p. 52). The distinction I have suggested may also be difficult to maintain in other contexts, for example in relation to photomontage, which involves the combination of disparate elements within a single frame.

3 Although my emphasis here is primarily spatial, it is worth noting that the dominant strand in discussions of found-footage cinema has to do with its historiographic potential. See, for 
In their recycling and reshaping of scenes from classical cinema, remix films like Peter Tscherkassky's Instructions for a Light and Sound Machine (2005) and Gregg Biermann's Spherical Coordinates (2005) can be aligned with what Thomas Elsaesser describes as a contemporary, second-wave cinephilia in which viewers are able to access, reframe, and re-present images across different contexts and media formats. ' 'Cinephilia [...]', he argues, 'has re-incarnated itself, by dis-embodying itself'. 5 The wholesale sampling of canonical cinema in contemporary video art, from Douglas Gordon's 24 Hour Psycho (1993) to Christian Marclay's The Clock (2010), arguably provides an aestheticized parallel to this disembodied cinephilia. However, as Christine Sprengler argues regarding contemporary art's recycling of Alfred Hitchcock's films, such works are not only cinephilic but also 'epistemophilic': that is, they 'add insight to aesthetic, historical, and even theoretical discourses on the cinema'. ${ }^{6}$

Accordingly, I argue that a number of contemporary experimental films work to illuminate the relationship between face and frame in classical cinema while exploring how face and frame might be reorganized into new permutations. Thus, these films arguably point not only to the face in cinema but also towards the diverse ways in which we face cinema itself in the post-cinematic era, encountering it at different scales, angles, and locations, from theatre to gallery to cellphone. ${ }^{7}$ Returning us to well-known screen faces and settings, these films invite us to reinhabit familiar cinematic worlds while reframing and rearticulating their spatial dimensions. At the outset, they engage us through a dynamic of recognition: it is the faces of the stars that draw us to these images, from Janet Leigh's panicky glances to Clint Eastwood's signature squint. In recycling such images, these experimental films highlight the face's role as cinephilic figure, but also look around and behind it-not simply to deface it but to initiate a fresh encounter, unlocking recognized, reified cinematic spaces so as to experience them anew and reflect on their constitutive codes and structures.

example, Anderson, Technologies of History; Danks, 'The Global Art of Found Footage Cinema'; and Russell, Experimental Ethnography.

4 Elsaesser, 'Cinephilia', p. 37.

5 Ibid., p. 41.

6 Sprengler, Hitchcock and Contemporary Art, p. 11.

7 Accordingly, the works discussed here span a variety of exhibition contexts: while all have screened theatrically, Peter Tscherkassky's films have been released commercially on DVD, Gregg Biermann's streamed via the online video-on-demand service Fandor, and Nicolas Provost's projected in gallery settings. 
William Wees has observed that 'found-footage films nearly always have the effect of bracketing the images and calling attention to them as images, as constructed representations, and therefore as something that can be deconstructed or "undone". ${ }^{8}$ Referring to the situationists' notion of détournement '(from détourner: "to turn away, to turn aside, to lead astray, to divert, to embezzle, to highjack”)', he goes on to discuss how seminal found-footage filmmakers (including Joseph Cornell, Bruce Conner, Mattias Müller, and Martin Arnold) have used détournement to magnify or, alternatively, to undermine the auratic power of Hollywood stars. However, my primary focus will be not so much on the Hollywood face in its own right, but more on the way that spatial relations are articulated around these recognizable figures. I want to repurpose détournement and use it in a more literal sense. By entering into a play with cinematic space, certain filmmakers have managed a spatial détournement, in which the frame is figuratively turned on its axis in order to produce alternative types of spatial relations. Here, face and space are, variously, folded in on each other, reoriented towards the frame's edges, or projected beyond them (not only into 'off-screen' diegetic space but also the non-representational 'off-frame' space defined by the material boundaries of the image). In the examples I discuss here, the face is crucial to this détournement of the frame. Each of these works involves a reorientation of face and frame via processes of disfiguration, transfiguration, and configuration.

In short, disfiguration operates by fragmenting or disrupting the image, transfiguration by remoulding it anamorphically, and configuration by placing images into new arrangements with one another. In each case, the dimensional qualities of the source images are transformed, as these works operate reflexively on the spatial qualities of classical cinema. As Rudolf Arnheim points out, cinema brings together two types of spatial organization, one two-dimensional and one three-dimensional. ${ }^{9}$ Narrative cinema depends upon the spatial limitations of the former aspect, which Arnheim refers to as 'pictureness': it is the weak 'spatial impression' of the film image that allows it to be articulated with other images, thus making montage possible. ${ }^{10}$ The films discussed here tamper with the relationship between

8 Wees, 'The Ambiguous Aura of Hollywood Stars', p. 4.

9 Arnheim, Film as Art, p. 59.

10 Ibid., p. 29. Stephen Heath makes a similar point when he argues, from the standpoint of suture theory, that 'the fiction film disrespects space in order to construct a unity that will bind spectator and film in its fiction' (Heath, 'Narrative Space', p. 101). For Edward Branigan, taking a cognitivist perspective, it seems that 'narrative is function which correlates imagined space-time with perceived space-time' (Branigan, Narrative Comprehension and Film, p. 62). 
'pictureness' and spatial depth. I argue that they produce consonant effects via strikingly different techniques, from fragmentation (disfiguration) to morphing (transfiguration) to juxtaposition (configuration). Foregrounding the mediality of the image - from the sprocket holes of celluloid stock to the algorithmic convolutions of the digital-they rearrange topological relations among images and image layers. ${ }^{11}$

As a privileged cinematic figure, the face intervenes in topological spaces by mediating between proximity and distance, flatness and depth. In this respect, the disarticulated, remoulded, and counterposed faces in these films both underline and amplify the dimensional ambiguity of the face in classical cinema. On the one hand, the close-up (commonly associated with the face) has the power to flatten space. As Mary Ann Doane (citing Gilles Deleuze and Béla Balász) comments, 'it is the close-up that is most fully associated with the screen as surface, with the annihilation of a sense of depth and its corresponding rules of perspectival realism.'. ${ }^{12}$ On the other hand, facial directionality and the associated geometry of the look is used to set up dramaturgical relations within a scene, connecting spatial depth with narrative potential. Accordingly, Paul Coates sees the traditional orientation of the 'three-quarter face' as crucial to mainstream cinema because it opens into narrative: 'the partial averting of the face grants it the status of something in motion, a rudder steering a set of actions. ${ }^{13}$

In the 'found footage' films discussed here, the dimensional variability of faces and spaces - their oscillation between flatness and depth - takes place via the (re)articulation of the frame. As Edward Branigan points out, however, there are myriad ways in which the term 'frame' can be understood. It can refer to, among other things, the image's outer edge, its composition or content, its perceived periphery or its perceived totality, or it can even describe the role of sound. ${ }^{14}$ I will use it primarily to nominate the physical boundaries of the image but also, where relevant, the visual field delineated by such boundaries as well as the various 'internal' frames produced within the image itself (through such means as revealing the edges of the filmstock, inserting 'vignette' or 'cameo' effects, and introducing fissures and edges, whether real or virtual). My conception of the frame thus maintains a central

11 Topology is determined by geometrical properties rather than physical ones — meaning that spatial relations between objects are maintained even when their size and shape is altered. Topology can thus be contrasted with the surface mapping of topography, in which scale remains constant.

Doane, 'The Close-Up', p. 91.

Coates, Screening the Face, p. 33.

14

Branigan, Projecting a Camera, pp. 103-113, 116. 
emphasis on its literal, material aspect but is also layered and somewhat flexible. The decontextualization of found-footage cinema, I argue, not only renders both face and frame as discrete fragments but also organizes them into new relationships of flatness and depth. Space is thus dynamically refigured (whether disfigured, transfigured or configured) - shaped into different forms as well as articulated around distinguishable faces and objects.

\section{The Disfigured Frame}

Peter Tscherkassky's Instructions for a Light and Sound Machine (2005) uses as its source material Sergio Leone's spaghetti western The Good, the Bad and the Ugly (1966), submitting it to a logic of overwriting and disfiguration. ${ }^{15}$ Working in a darkroom studio with strips of film, Tscherkassky uses a laser pointer to optically print selected regions of different frames onto black-and-white stock. Repeating this process many times over, he produces extraordinarily dense and layered composite images. This process is emphatically analogue-based, an engagement with the raw technicity of celluloid cinema that is reflected in the film's matter-of-fact title as well as its exploration of film's physical boundaries - in particular, the boundary constituted by the frame. Although Instructions for a Light and Sound Machine arguably seems more concerned with frames than with faces per se, there are a number of key moments at which Sergio Leone's original orchestration of faces and landscapes becomes a springboard for experiments with spatial dynamics.

Tscherkassky's film opens with an image showing a man opening a window and peering through a telescope. This image, rendered in negative and repeated over and over again throughout the first part of the film, appears to motivate a chain of 'reverse shots', although there are no other cues to confirm a shared diegetic space. Following an array of cameo images drawn from various moments in the source film, we are presented with a wide landscape shot. A face now swings into frame, obscuring most of the backdrop. Although grainy and unstable, and transposed into black and

15 Writing on Tscherkassky's work tends to treat it as a kind of 'critical cinephilia', which works by engaging with, rather than rejecting, classical cinema. See Balsom, 'A Cinephilic Avant-Garde', p. 264. In Tscherkassky's Outer Space and Dream Work, argues Michele Pierson, 'the critical work of analysis begins [...] with the intensification of the sensory experience of cinema' (Pierson, 'Special Effects', p. 44). For Alexander Horwath, 'Outer Space is no longer the "parallel space" of the avant-garde, but in fact the “world space” of cinema' (Horwath, 'Singing in the Rain'). 
white, this shot is recognizable as the opening image of The Good, the Bad and the Ugly. It is followed by a chain of similar close-ups and medium close-ups selected from different scenes, showing hard-faced men staring adversarially into off-screen space. Deployed out of context, these shots of faces have no clearly identifiable corresponding reverse shots-are they looking at each other or at some other object or vista? This sequence implies a mysterious composite space beyond the frame, crisscrossed by looks and counterlooks.

In this way, Instructions for a Light and Sound Machine references the source film's obsessive exploration of faces and landscapes via widescreen compositions. ${ }^{16}$ In Leone's cinema, the intercutting of extreme facial closeups with remote wide shots invites us to read one through the lens of the other: the immobilization of the face, its hypermasculine inexpressiveness, turns it into a kind of landscape. In this sense, faces in Leone's films are thoroughly infiltrated by space. Reworking this material, Tscherkassky amplifies the air of spatial uncertainty that already haunts the original film. In the source film's opening 'face-off', which Tscherkassky samples heavily, the characters appear almost to be looking down the barrel of the lens. The spatial relations between the extreme wide shots and confronting close-ups are eventually established, but it takes time for the orientation of the 180-degree axis to become clear. Yet in a sign of its tenuousness, Leone also crosses this axis in the opening scene, briefly reversing the screen direction of the advancing combatants just before they reach each other. Ultimately we realize that, despite appearances, these men are not moving along a linear vector of action: rather than confronting each other, they are converging on the same building, where they hope to capture another character in order to earn a bounty.

In resampling and re-editing this footage, Tscherkassky magnifies its sense of uncertainty: the unreadability of Leone's screen faces translates into an intensified unreadability of cinematic space. At times, given the directness of the characters' stares (parallelled by the direct 'look' of the telescope, which seems almost to be aimed at the viewer), space itself threatens to flatten out altogether: that is, the characters appear to stare not towards each other, thus opening up spatial dimensionality, but towards the two-dimensional plane of the film screen. Tscherkassky thus takes

16 Erika Balsom comments on Tscherkassky's use of CinemaScope in relation to Leone's source material but also positions it within another tradition of widescreen aesthetics, which works by 'fragmenting the image into multiple planes or using its vastness to orchestrate an intricate visual spectacle' (Balsom, 'A Cinephilic Avant-Garde', p. 265). 
advantage of the facial geometry of the spaghetti western-the network of inscrutable looks and counterlooks that orchestrate space and pave the way for the gunfire to follow. Appropriately, in Instructions for a Light and Sound Machine, the series of unanchored facial close-ups described above is followed by a fusillade of gunshots. Rapidly interspersed shots of gun barrels cross the frame, both as positive and negative images, emphatically cancelling out the preceding images of the face while underlining the original film's alignment of looking and shooting.

At the same time, Tscherkassky breaks apart the integrity of the face itself, deploying the same technique he used in earlier works, including the much-discussed Outer Space (1999). Using a complex optical printing process, Tscherkassky selects and layers elements of different frames, radically recomposing his sampled material. The result is a barrage of images in which frames, bodies, and faces are multiplied atop one another, becoming unstable, fragmented, and, through the collapse of depth and compositional order, dramatically dis-figured. As Christa Blümlinger has observed, Outer Space also involves an intensive exploration of faciality. Drawing footage from horror movie The Entity (SidneyJ. Furie, 1982), in which Barbara Hershey plays a woman who is tormented (and sexually assaulted) by an unseen supernatural force, the film breaks up Hershey's face with flurries of shadows and multiplies it across the frame, even as the frame itself seems to explode. Sprocket holes and framelines become visible, as both face and frame are violently shattered and refracted. Blümlinger points out that in Outer Space, the cinematic spectacle of violence against the female body is, according to a dynamic of repression and punishment, directed instead against her face. Like the shower scene in Hitchcock's Psycho, she argues, Tscherkassky's film depends on 'the figurative opposition of the female face and the space that surrounds it'. ${ }^{17}$ This figurative opposition, however, is projected into the very materiality of the celluloid, so that the threat comes not so much from off-screen space as from off-frame space. ${ }^{18}$ That is, the narrative threat of off-screen space (which lies outside the frame but within the diegesis) gives way to the purely formal threat of off-frame space (which is defined by the technical boundaries of the image). In Outer Space, the frame itself has an ambiguous mediating role, both receding from and advancing into view. At

17 Blümlinger, 'Found Face'.

18 James Cahill suggests that these films work by 'foregrounding the inherent tension between interiority and exteriority' in Cahill, 'Anacinema', p. 94. Similarly, Akira Lippit argues that Outer Space delineates neither outer nor inner space but the space between the two, the imaginary space that opens between a film from a film, ex-film' (Lippit, Ex-Cinema, p. 9). 
one point, for example, the black ground of the image becomes populated with unmoored facial fragments in the form of multiple vignetted eyes. The rectangular logic of the film's physical boundary is thus suppressed, as each fragment produces its own diffuse 'frame'. Elsewhere, however, the image is marked by an excess of linear framelines, supplied by superimposed windows, mirrors, doorways, and, not least of all, by the edge of the film strip itself, which intrudes violently upon the scene.

We might, then, see Instructions for a Light and Sound Machine as an attempt to do for the male face what Outer Space does for the female. In this case, the challenge of the masculine stare in The Good, the Bad and the Ugly is deflected into an uncertain space beyond the frame, refiguring the relationship between the film's hard-faced characters and the spaces they seek to command. Furthermore, the film channels both real and implied aggression and directs it against the face. As the film reaches its crescendo, the frame stutters and slips while images of facial anger and violence (which include a character having his eyes gouged) seem to be layered atop one another. In this instance, Tscherkassky combines elements of collage and montage: on the one hand, he allows frame lines to split the image along the horizontal axis, producing discontinuity and disjuncture within the frame; on the other hand, he uses rapidfire montage to create a flickering effect, alternating frames at such speed that they appear to infiltrate each other's figurative spaces.

At another point, the face-frame relationship is approached more directly, as a lynching scene featuring Eli Wallach (in the role of Tuco, or, as per the original film's title, 'the Ugly') is radically reframed. Dangling from a tree, Wallach's countenance flickers and slips until finally his swinging head and face, framed by the noose, appears to become dislodged from its profilmic backdrop and sways back and forth across the visual field, occupying its own roughly cropped frame. Once again, Tscherkassky plays with vertical orientation, allowing framelines to roll up across the image but also superimposing and interpolating other objects and environments, including images of fleeing and captured animals, a skeleton in a coffin, a horse-riding figure, and Clint Eastwood's character (Blondie, aka 'the Good') taking aim with a rifle (in the original film, this character is attempting to sever the rope suspending Tuco, although here that moment of release appears eternally suspended). The footage of the swinging man is also duplicated, overlaid, and even inverted, so that the image appears, in a sense, to have been multiplied by itself. Ultimately, Wallach's embattled figure is confronted by the material substrate of the film: not only framelines, sprocket holes, and broken edges but also the segments of leader marked 


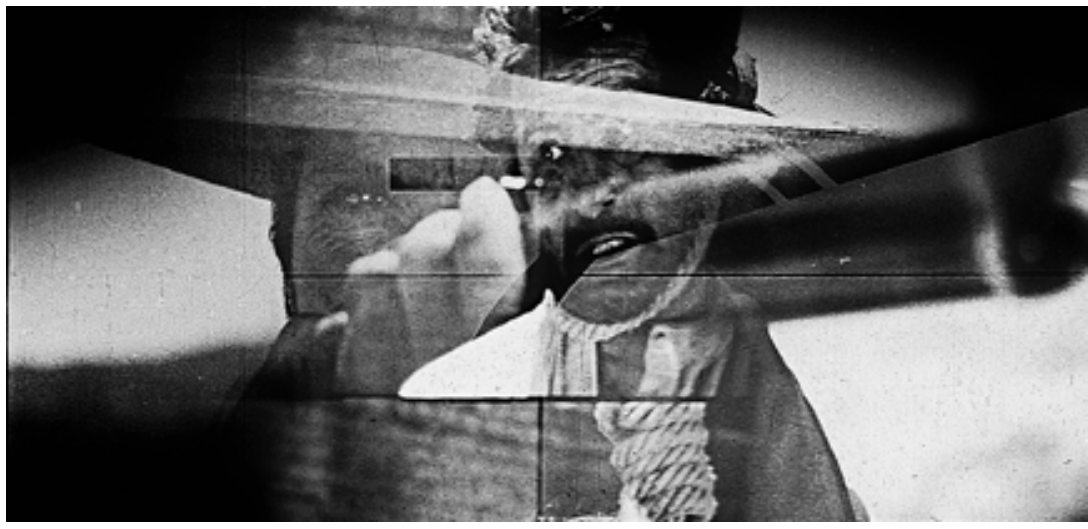

7. Still from Instructions for a Light and Sound Machine, Peter Tscherkassky, 2005. 17:00. Courtesy of the artist.

with the sync sound countdown and, in a neat pun on the framing of Tuco's predicament, the words 'PICTURE', 'HEAD', and 'TAIL'.

These examples can be considered a specific type of what Pascal Bonitzer calls 'deframing'. Deframing refers to the off-centre angles and frames of modernist cinema, which produce empty spaces and push human figures to the periphery of the frame. ${ }^{19}$ Edward Branigan describes deframing as a kind of 'antisuture' that produces disfigurement: 'In a deframed image, something human has been lost or drained away, cruelly disfigured, but the spectator has arrived too late to witness how the frame/lines were broken and used "as a cutting edge".'20 Although Bonitzer's term is not intended to refer to visual fragmentation per se (Bonitzer notes that 'the fragmentation of figures is a well-known cinematic device'), Tscherkassky's distinctive approach produces a kind of deframing through fragmentation. ${ }^{21}$ In Instructions for a Light and Sound Machine, deframing radically decentres the human body and face while multiplying the film's arsenal of 'cutting edges'. This marginalization of the human is mirrored at the structural level: the protracted 'remix' of Tuco's lynching, which Tscherkassky places at the film's midpoint, is followed by a passage of abstraction and then an elongated sequence in which the use of negative, inverted, superimposed, and otherwise unstable images serves to dissolve the figure of Tuco running back and forth among a field of grave markers. Death seems to be inscribed in the very images, as the body and face are disfigured, robbed of their power to orchestrate cinematic space. 
Thus, both face and frame are refigured, multiplied, and dissolved via a process of cinematic collage. As in Outer Space, the face is confronted not only with off-screen (diegetic) space but also off-frame (abstract) space. It is at once flattened and multiplied, as the space beyond the frame seems somehow to infiltrate the image, causing a fracturing of both frame and face. In one arresting moment in Outer Space, Hershey's face is multiplied across different instants, so that we see one face turning into the space occupied by the next one, and so forth. Thus, dislocating the face in time paradoxically endows it with additional volume (in this sense, Tscherkassky's approach both borrows and diverges from the de-dimensionalizing techniques of cubist art). Similarly, in Instructions for a Light and Sound Machine, we are conscious that the faces we see are imprinted on flat celluloid, but the surplus spatial movements of the damaged frames appear to suggest the intervention of forces occupying three-dimensional space (whether the mechanism of the camera and projector, or the less clearly defined 'outside' of the frame). In this way, Tscherkassky's work reminds us of the two-dimensional flatness of the frame and its material limits (and hence its remoteness from the spatial plenitude of the profilmic scene) but also, in refiguring the frame, succeeds in conjuring up depth-oriented spatial relations beyond it: here, space returns with a vengeance. Although Tscherkassky's exploration of the celluloid frame aggressively foregrounds analogue materiality, his attention to cinematic space is nonetheless echoed in certain digitally based remix works, such as the one I will discuss in the following section.

\section{The Transfigured Frame}

Gregg Biermann's film Spherical Coordinates (2005) pursues a completely different approach in order to explore the limits of the frame and the face. The film recycles a short sequence from Psycho (Alfred Hitchcock, 196o) in which the character of Marion (Janet Leigh), who has stolen money from her employer, drives through a rural landscape and into a city, and is briefly pulled over by a policeman along the way. However, this familiar scene is subjected to an extraordinary transformation, taking it far from its celluloid origins. Using digital software, Biermann 'projects' the original sequence into a virtual sphere, distorting the image to the point where the edges of the original frame curl around to meet each other. That is, although the image we see is technically two-dimensional, it appears to be stretched across a curved, concave surface. Using a virtual 'camera', Biermann then pans across the surface of this curved image. The frame is thus revealed 


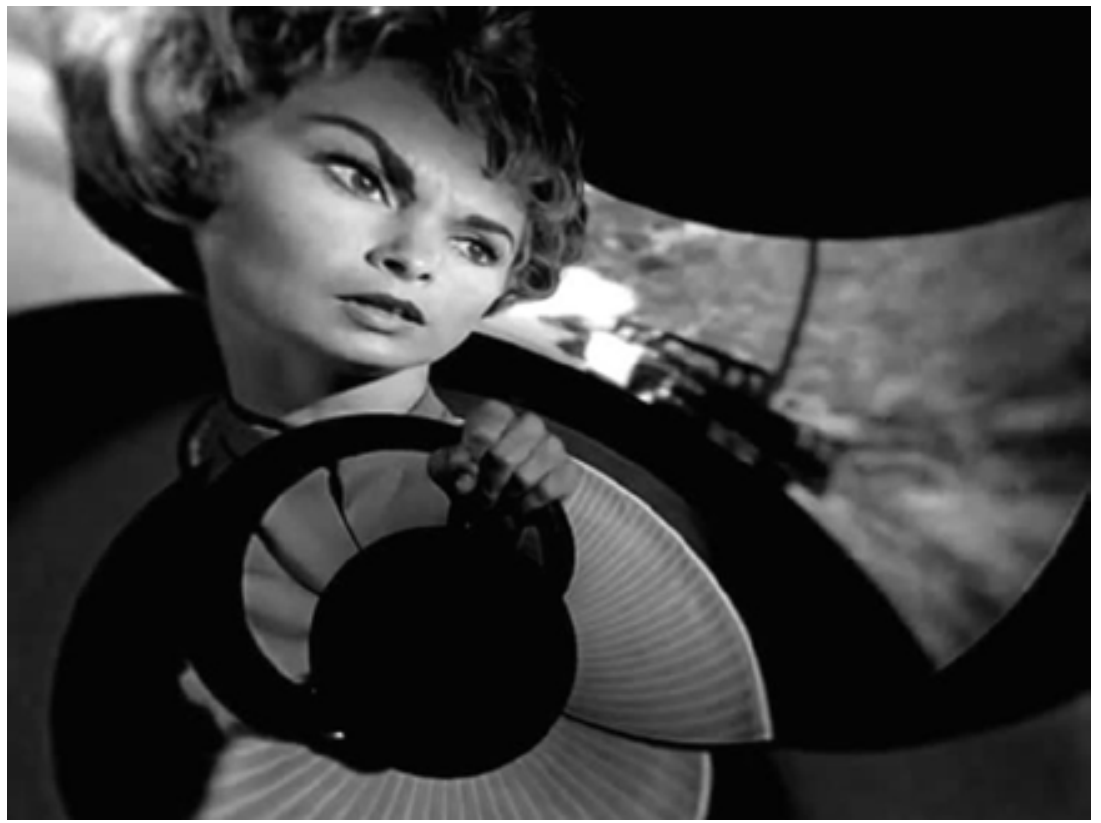

8. Still from Spherical Coordinates, Gregg Biermann, 2005. 04:00. Courtesy of the artist.

as a fragment, but one that is folded into a self-referential totality. Here, the face's place within this radically distended frame, as well as its role as an element in traditional shot-reverse shot structure, is uncertain. The virtual camera movements that pan across the surface of the sphere turn the face on its head, pushing it to the edge of the frame and making it balloon comically. In the process, the conventional relationship between face and space (involving the careful juxtaposition of the reaction shot and the spatial environment) is overturned, as each is folded into the other.

Here, the face is neither fragmented nor multiplied. Instead, it is transfigured, becoming coterminous with its surroundings. In Spherical Coordinates, there is no face, and everything is face. The conventional figuration of the face collapses as figure and ground become equivalent. In the process, screen spatiality is compressed and flattened. The planar ontology of the source images is foregrounded, along with the illusory depth of their digital reincarnation: instead of a face standing out against a backdrop, we see a two-dimensional plane projected across a virtual surface. Indeed, the film's invocation of geometrical coordinates suggests not only the curvature of that surface but also its digital mapping.

At the same time, the constant movement of the virtual camera suggests the orientation of a POV shot, looking from within the car (and hence 
aligns with Marion's fearful, paranoid glances at the space outside). This is supported by the distortion of the images, which makes space appear concave. From one perspective, the filmic material is organ-ized in the form of a giant eyeball, which scans anxiously across its environment. The black circles that mark the top and bottom of the wraparound frame might thus serve either as metaphorical pupils or optical occlusions - the inescapable blind spot that haunts human vision. However, given that Marion's face, monstrously distorted, remains within the frame, we have also the sense of being on the outside of the space, looking in. We thus face inwards and outwards, as if gazing at the image from both sides. Meanwhile, the spinning of the transfigured frame emphasizes and enhances circularity, so that the face itself becomes another rotating element, along with the steering wheel, the dark circles above and below the 'frame', and, by implication, the spinning wheels of the car itself. In this way, the face and the vehicle are folded into the same loop: perception, navigation, movement, and affect all play out across curved surfaces. Indeed, even as Marion's face becomes just another object within the frame, the film's vehicular travelling shots seem increasingly facialized, as the images of cars and city streets resolve into vortices punctuated by dark holes - crude approximations of faces, in other words. These in turn seem to echo the dark glasses worn by the police officer as he peers into the car.

Such images recall Deleuze and Guattari's account of the 'abstract machine of faciality' which 'produces faces according to the changeable combinations of its cogwheels'. ${ }^{22}$ For Deleuze and Guattari, the face is a historical construct associated with reification and control. Faciality, which imposes semiotic meaning and subjectification, is produced by the 'despotic and authoritarian concrete assemblage of power. ${ }^{23}$ The master metaphor for this machine is a white wall punctuated with black holes. Facialization is engendered by the 'black hole/white wall system' via a process of abstraction in which meaning and affect are locked down. Beyond its literal presentation of Marion's face, Spherical Coordinates produces an array of facializing effects that orient pale surfaces around black holes (the 'top' and 'bottom' of the looped frame). These effects serve to evoke notions of recognition, detection, and authority - particularly in relation to the hostile gaze of the police officer. At the same time, the rapidly swirling camera movements at the end of the film introduce a further transformation in which Marion's distorted face appears to fold into its surroundings. The mobility and reversibility of these 
images means that this abstract 'face' is always flirting with 'defacialization' by dissolving into something less determinate: a space, an environment, an excrescence. ${ }^{24}$

Accordingly, one can also see another potential metaphor in this sequence, which gestures beyond the visible body, foreshadowing the infamous shower scene and its aftermath. Specifically, the turning of the image around a dark circle recalls the close-up of water, mixed with blood, draining down the plughole at the Bates Motel. This effect is further enhanced by the swirling, heavily processed dialogue that accompanies Biermann's film. Biermann's manipulation of sound and image amplifies the embedded significance of this intermediate scene, reframing Marion's anxiety regarding her guilty past as a premonition of her future doom. The incessant movement of Spherical Coordinates thus recalls Bonitzer's notion of deframing in two senses: in visual terms, it pushes the human form to the limits of the frame, dehumanizing it; and in narrative terms, it foreshadows the emptying out of the original film's sympathetic investment, as the protagonist's life goes figuratively down the plughole. Yet, in keeping with the circular logic of Spherical Coordinates, this visual metaphor leads not simply into defacialization; it also serves to lead us back to the face via another route. In Hitchcock's Psycho, the image of the plughole dissolves to an extreme close-up of Marion's lifeless eye. The shot pulls back to place the eye in the context of Marion's face, emptied of expression. The circuit of the drain leading to the eye leading to the face is a crucial moment in Hitchcock's film, and Biermann's orchestration of eye, face, and environment gestures obliquely but unmistakeably towards it. Once again, the 'abstract machine' of faciality reasserts itself as we move back and forth between facialized spaces and spatialized faces.

Finally, we might suggest another twist in Biermann's playful détournement of face and frame, via the concept of interface. Slavoj Žižek uses this term to refer to the blending of subjective and objective shots within the same frame, by way of reflections, superimpositions, or other types of composite images. ${ }^{25} \mathrm{He}$ suggests that such interfaces produce a 'spectral dimension', via which repressed elements (whether textual, ideological, or pathological) are brought to the surface. ${ }^{26}$ Žižek cites examples from Kieslowski's Blue (1993), in which an approaching figure is reflected in the protagonist's eye, and The Double Life of Véronique (1991), in which Véronique's 
psychological state is evoked via the anamorphic distortions created by a train window and a glass ball. ${ }^{27}$ What has been excluded from the frame thus returns via the interface, as the shot is haunted by its reverse shot. The sequence sampled by Biermann contains just such an interface in the form of Marion's rear-view mirror, where the figure of the following patrolman is clearly visible.$^{28}$ Despite being extracted from its original narrative context and placed against a giddily spinning backdrop, the internal frame of the rear-view mirror is nonetheless successful in indexing Marion's sense of anxiety. Regarded in its entirety, Spherical Coordinates might also be viewed, like the motif of the glass orb in The Double Life of Véronique and Citizen Kane (Orson Welles, 1941), as an anamorphic interface that reflects and magnifies Psycho's circuit of guilt, repression, and punishment.

Yet Biermann's recycling of the film fragment leads not only towards the Žižekian notion of interface, with its hermeneutic implications, but also towards the notion of a purely digital interface, which reflects in turn on questions of mediatic transfiguration. Eivind Røssaak, in his analysis of the 'algorithmic turn' in post-cinematic media culture, singles out Biermann's work as "software cinema" because it so insistently explores a found sequence of film images according to a preprogrammed software feature or "special effect". ${ }^{29}$ In Spherical Coordinates, he writes, 'It is as if a camera is analyzing the manipulation of the image itself'. ${ }^{30}$ The image is thus rendered as a kind of interface, which both indexes and conceals the algorithmic processes underpinning it. In this context, the face is both central and peripheral. The image-as-interface operates according to a dynamic of facing (defined by subject-object interaction) that parallels but differs from the other gestures of facing represented within the film itself (facing the mirror, facing the road, facing the camera). It suggests a zone of interventions and encounters, a surface for touching as well as looking. By investing Hitchcock's familiar images with the illusion of volume and traversing them with a virtual 'camera movement', Biermann renders the image as a control surface while underlying the gap between the image-asinterface and the underlying mutability of its digital code. The plastic, tactile quality of Spherical Coordinates thus evokes the 'hands-on' manipulation of the image, transforming perspectival space (and the face as one of its key

27 Ibid., p. 52, $5^{0 .}$

28 This embedded frame, as Kaja Silverman points out, signals Marion as 'doubly inscribed' by the law, since the image of the pursuing cop appears both in the frontal shot of Marion and in the reverse shot of the mirror (Silverman, The Subject of Semiotics, p. 209).

29 Røssaak, 'Algorithmic Culture', pp. 195-196.

30 Ibid., p. 197. 
elements) into interfacial space, where the relationship between flatness and depth is endlessly negotiable.

Like Instructions for a Light and Sound Machine, Spherical Coordinates encourages both cinephilic and analytic engagements with its sampled text and probes the relationship between two- and three-dimensionality. Creating a push and pull between face and frame, Biermann's film flattens and opens out cinematic space, as if inviting viewers to inhabit the images, to view them from the other side. Yet rather than breaking up face and frame, Spherical Coordinates treats the frame-as-fragment as the basis for a virtual totality. The incessant re-cycling of the image leads both towards the fantasmatic (the world of Marion's character in Psycho, her guilty past and tragic future) - and also out of it, towards the algorithmic. Via a singular type of spatial collage, Biermann juxtaposes the film frame with itself, making visible its two-dimensional boundaries while projecting it into an alternative, three-dimensional virtual space. In the process, other boundaries (the boundaries dividing figure from ground and face from not-face) are drawn into question. Upturning classical cinema's compositional logic, Spherical Coordinates reads the cinematic face in and through its spatial surroundings, causing dizzying movements into and through the image. The face and the act of facing are both transfigured as the sampled sequence becomes a world in its own right.

\section{The Configured Frame}

My next example draws upon more conventional means but achieves equally dizzying results through a logic not of disfiguration or transfiguration but one of configuration. Nicolas Provost's film Gravity (2007) is a work of montage, based upon the rapid intercutting of found footage. Yet while Provost, unlike Tscherkassky and Biermann, does not intervene within the frame itself, the speed of oscillation between images produces illusory spatial effects, exposing invisible seams within the frame. The source material for Gravity betrays the film's cinephilic dimension: it involves a series of fraught romantic encounters drawn from a range of iconic auteur films including Vertigo (Alfred Hitchcock, 1958), Hiroshima mon amour (Alain Resnais, 1959), and Blue Velvet (David Lynch, 1986). Cross-cutting between scenes from these films at an extremely rapid rate, Provost synchronizes the characters' actions of approaching, embracing, and kissing so that the movements take on an uncanny, flickering consistency. They are both continuous and supremely disjunctive. 
The face is central to this diachronic articulation, because Provost places heads and faces from different films close enough to suggest an ongoing chain of graphic matches. Filmic fragments collide, and the figurative anchor of the face helps to bind them together. But Gravity also, through temporal fragmentation, blends and blurs the functions of face, body, and frame, both revealing and exaggerating the way that each can, in a narrative context, serve as a stand-in for the others. Through a telescoping effect, the frame is reduced to the body, which is reduced to the face. Here, looks and counterlooks across different films link unrelated bodies and incommensurable spaces, as frame faces frame. Gravity's facial logic is thus dynamic and transitive, deploying 'face' not only as noun but also as verb. Catherine Fowler has commented on the significance of physical gesture in found-footage video works such as Christian Marclay's The Clock (2011), arguing that it is not facial expressivity but bodily movement that animates them. Writes Fowler, 'these artists grasp and seize gestures, observing how they mediate between the film's past and the viewer's present'. ${ }^{11}$ Yet the spatial dynamics of Gravity suggest a blurring of any firm distinction between face and gesture. For this is also a film about the act of facing, a fact that is underlined by the alignment of dynamic movements, in particular by the action of characters turning to embrace and kiss each other. The role of the cinematic face, Gravity reminds us, is to face and be faced.

At the same time, Gravity's orchestration of facing eventually directs the performers' faces away from the camera as they collectively orient themselves towards the privileged moment of the kiss. Steven Jacobs, in his analysis of Gravity, links the cinematic kiss with stillness and closure: 'A favourite motif for stills, a kiss scene implies the transformation from film to photograph, from movement to stasis. ${ }^{32}$ Yet as Jacobs also observes, Provost's montage draws substantially upon Hitchcock's staging of kiss scenes, 'which involve actors turning in the manner of a waltz'. ${ }^{33}$ Thus, by linking together a chain of these cinematic moments, Provost maintains a kinetic momentum, drawing out the gestural movement of the kiss. The extended action of the kiss also works as a figure at the textual level. Gravity stages a promiscuous frenzy of the cinematic, via which different films and film moments come into erotic contact. It is not only faces but also frames that touch each other in Gravity. Throughout the remainder of the film, Provost allows his human figures (the recognizable stars of classic films) 
to separate and embrace again, in a choreographed negotiation between intimacy and distance, a series of facial exposures and occlusions.

In this respect, Gravity recalls Les LeVeque's much-discussed film 2 Spellbound (1999), which accelerates Hitchcock's Spellbound (1945) to breakneck speed and alternates the horizontal orientation of selected frames, producing symmetrical superimpositions. The mirroring of these superimpositions and their resemblance to Rorschach blots references 'Spellbound's narrative concerns with psychoanalysis' ${ }^{34}$ However, as Sharon Tay and Patricia Zimmerman argue, the systematic 'algorithmic' technique used to extract and modify the footage simultaneously renders the image as 'interface' and frees desire from 'psychoanaly tic codifications': in 2 Spellbound, 'desire is in the machine, not the image'. ${ }^{35}$ The abstract patterns that emerge from these algorithmic processes 'underscore the image as a spatialized zone' $3^{6}$ Within this zone, I suggest, new space-face possibilities present themselves. As characters lean in to kiss each other, the flickering reversals render them as mirrored ghosts who are simultaneously kissing themselves. Throughout the film, faces tend to overlap with and inhabit other faces, blurring identity and spatial autonomy. Arguably, 2 Spellbound's clone-faces are synecdochic for the film itself, figures of its mirrored configuration.

In a less obvious way, Gravity's underlying logic is also algorithmic. Although it resembles conventional montage, the editing appears determined by a schematic pattern of alternation. This pattern changes speed at key moments but maintains a regulated, metronomic rhythm. The film thus resembles a database of video clips fed into a rule-based system, although it is clear that these clips have been carefully synchronized to produce spatial effects. Gravity's aesthetic thus exists somewhere between the precise temporal orchestration of montage and the automated logic of the algorithm. The key difference between 2 Spellbound and Gravity lies in Provost's more deliberate use of editing to produce spatial depth. In 2 Spellbound, the acceleration and symmetrical arrangement of the images compresses the frame, while Gravity's disorienting effect depends on a more ambiguous oscillation between flatness and depth. The use of shotreverse shot conventions and the repetition of pivoting movements open up cinematic space, even as the juxtaposition of non-contiguous locations threatens to close it down. 
In this uncertain dimensional field, the film is held together by the viewer's attempt to read the 'figure' (both face and body) across disparate spaces. If 2 Spellbound treats spaces and bodies as contingent details, raw material to be processed along with the frame itself, Gravity keeps the human figure at the centre of its spatial operations. The movement of facing can be regarded in its own right as a type of figure, a sensible and recognizable form unfolding in time. Yet this figurative movement also has an abstract dimension, tracing a dynamic line that leads to the interchangeability of bodies, faces, and spaces. Characters oscillate between self and other, male and female, colour and monochrome. Grasping the form and identity of these figures is an ongoing challenge for the viewer.

Furthermore, the spatial integrity of the frame is constantly undermined. Although Provost does not modify individual frames, the quick oscillation between shots produces new seams and splices within the image as visual elements appear to traverse the boundary of the edit, 'jumping across' from one frame to another. We are witness to a kind of illusory collage taking place inside the frame. In one example, a character from Hiroshima mon amour apparently reaches out to caress a character from Blue Velvet; in another, the luminous pulse of Kim Novak in Vertigo alternates with the luminous pulse of a lamp in another film, so that together they seem to traverse cinematic space and time.

This dynamic movement of faces, facing, and intercutting places $2 \mathrm{D}$ and ${ }_{3} \mathrm{D}$ space in tension, and thus parallels Tscherkassky and Biermann's films, which use different techniques to similar ends. On the one hand, the interpolation of images from different films underlines the flatness of the image, since the illusion of a consistent three-dimensional field of action is eroded. On the other, the graphic alignment of different faces, bodies, and objects, and the hypnotic tracking movements around them, cause them to stand out from the backdrop and produce new spatial configurations defined by the impression of virtual depth. Space thus seems to have been simultaneously expanded and compressed. Here, the face as figure is central to the effect of the film-it is a pivot around which the film orchestrates different spaces, shots, and frames. Gravity thus depends upon a logic of configuration, of figuring with, in which the juxtaposition of faces and frames produces striking spatial transformations.

A very different logic of configuration shapes Gregg Biermann's Magic Mirror Maze (2012). In this case, the juxtaposition of frames is primarily spatial rather than temporal, as the climactic 'hall of mirrors' scene from Orson Welles' The Lady from Shanghai (1947) is replicated across multiple 


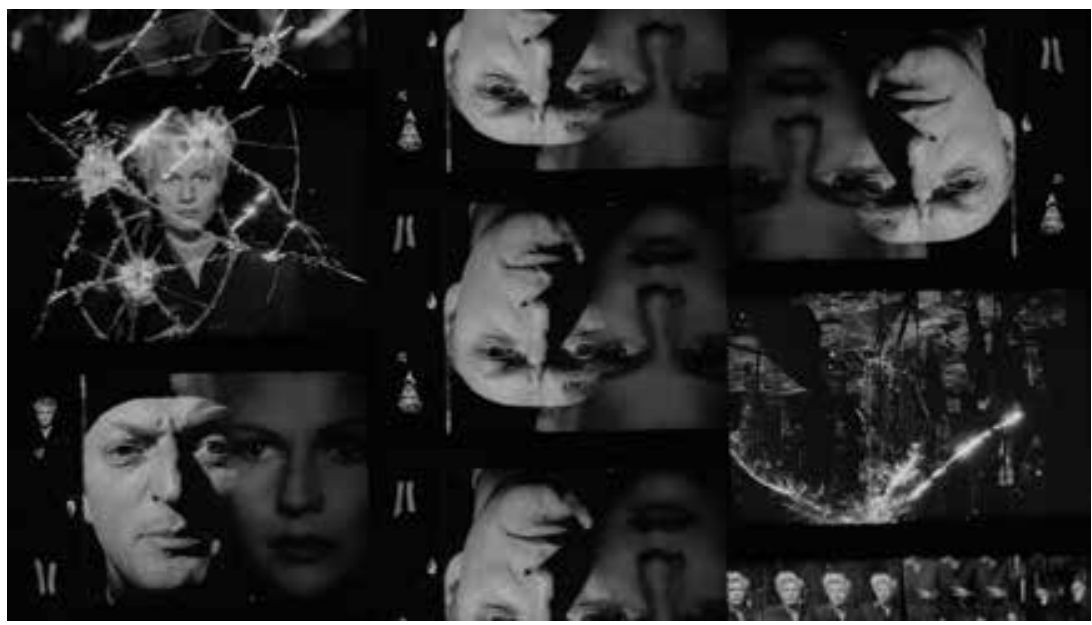

9. Still from Magic Mirror Maze, Gregg Biermann, 2012. 05:00. Courtesy of the artist.

frames within the frame. These are initially laid out in a three-by-four grid. Later in the film, this format is varied, and the frames are arranged in twoby-three or two-by-two formations, with each strip of frames offset either horizontally or vertically from its immediate neighbours. Added to these frames are, of course, the frames constituted by the mirrors depicted in the source film. This arrangement of frames within frames generates both formal and spatial confusion, as it is sometimes difficult to tell whether the divisions are internal or external to any given image. In Welles's film, the mirroring of faces and figures across the screen emblematizes the deceptiveness of the characters and their milieu. Biermann's algorithmic multiplication of this framing effect projects this deceptiveness into the material form of the digital image. When the femme fatale and her estranged husband open fire, the cascades of shattering glass evoke not only the collapse of the protagonist's world but also the disintegration of the image into its component pixels.

Magic Mirror Maze's distinctive effect depends on the intermingling of frames and the resulting push-and-pull between different spatial systems. As in Spherical Coordinates, two types of interface can be identified here. In this case, these comprise the original film's Žižekian mirror-interface, which reflects the characters' own duplicitousness and returns it to them as a collapse of subjectivity, as well as Biermann's supplementary windowinterface, which duplicates the frame and distributes it across the screen's visual field. In the latter sense, Magic Mirror Maze points towards the contemporary dominance of what Anne Friedberg, discussing the layered 'windows' of the computer interface, describes as a 'post-perspectival' visual 
regime. ${ }^{37}$ In the 'windowed' environment of the digital screen, there is no necessary spatial relation between frames, nor any assumption that any given frame will open into a representation of three-dimensional space.

The digital-interface effect of Biermann's film flattens out the already compromised space of the 'hall of mirrors' scene, diminishing its sense of representational volume. Yet depth is not banished altogether. Biermann introduces his own artifical sense of depth at certain points by juxtaposing shots of different scales in different frames. In a sequence towards the beginning of the film, for instance, a number of facial close-ups are interspersed with long shots showing an array of reflected figures. Here, proximity and distance are arrayed across the visual field and modulated in complex ways, as the close-ups are brought to the centre of the master frame or distributed around its edges. Biermann also selectively inverts frames along their horizontal axis, setting up new dynamics of facing and looking between frames. At one point, a close-up of Rita Hayworth's face occupies selected frames, her eyes tilted slightly upwards, so that she seems almost to be gazing up (or down) at her transposed counterpart. Furthermore, under the pressure of the film's dynamic spatial inversions and temporal delays, the frame boundaries become zones of indeterminacy, across which bodies appear to become fused with their mirror counterparts. At one point, Rita Hayworth's eye, situated in the centre of each frame, becomes the pivot around which the images flip. Here, the face wavers precariously between figuration and abstraction. The spatial reconfiguration of frames thus produces both two-dimensional and three-dimensional effects, prompting a kind of ontological hesitation between the topologies of the mirror, the frame, and the digital interface.

\section{Conclusion}

Biermann and Provost's films thus illuminate cinema's new spatial coordinates in the era of the algorithm and the interface, as both face and frame are folded into the post-perspectival regime of the digital screen. These works are aligned with 'the new cinephilia of the download, the file swap, the sampling, re-editing and re-mounting of story line, characters, and genre'. ${ }^{8}$ Yet the other side of this contemporary cinephilia arguably involves a return to the technologies and settings of analogue cinema, as 
exemplified by Tscherkassky's attachment to celluloid materiality and to the Cinemascope format. Here, spaces and faces are no less emphatically unhinged from their original contexts, as Tscherkassky constructs a postperspectival aesthetic based purely on the film strip and its relationship with light. Despite utilizing very different technologies and techniques, then, these various works display striking parallels. Regarded collectively, they represent a remarkable alignment of aesthetic practices and conceptual implications at the conjunction of analogue and digital cinephilia. By disarticulating recognizable cinematic faces from their narrative and scenic contexts, these films render them as fragments, allowing viewers to encounter familiar images in unfamiliar alignments and enabling new articulations in flatness and depth. They operate by disfiguring the face, by multiplying it across the frame, by transfiguring and distorting it, or by placing it into new configurations with other framed faces and spaces.

Such works thus recall Barthes' distinction between figuration and representation. For Barthes, figuration describes 'the way in which the erotic body appears (to whatever degree and in whatever form that may be) in the profile of the text [...]'.39 Representation, by contrast, is 'embarrassed figuration', in which relations of desire are contained within fictional or represented worlds. ${ }^{40}$ The notion of boundedness is crucial to Barthes' distinction: representation is 'when nothing emerges, when nothing leaps out of the frame: of the picture, the book, the screen'. ${ }^{41}$ The project of the films I discuss here is to re-figure the face and its spatial relationships. These works transform the framed spaces of narrative cinema and also face beyond them, opening the frame into abstract spaces that oscillate between flatness and depth. The implications of this oscillation are both experiential and critical: on the one hand, it allows viewers to reinhabit familiar cinematic worlds, as if stepping across a dimensional threshold; on the other, it encourages them to consider how cinema apprehends and articulates space.

Although found-footage films often display refigurations of cinematic space, these particular works' intensive focus on the face gives such refigurations a conceptual and aesthetic twist, foregrounding the face's importance as a point of spatial articulation. As film theoretical debates indicate, the cinematic face can produce dimensional ambiguity through its capacity to open up spatial relations (in the shot/reverse shot, for example) and 
to collapse them (in the close-up). Playing on this ambiguity, these films frame the face not just as a marker of identity, or site of affect, but as a spatiotemporal function. The face, these works remind us, faces. By teasing apart and rearranging the relationship between cinematic faces and spaces, they turn cinema back on itself, bringing it face to face with its own complex dimensional ambiguity.

\section{Bibliography}

Anderson, Steve F. (2011). Technologies of History: Visual Media and the Eccentricity of the Past. Hanover, NH: Dartmouth College Press.

Arnheim, Rudolf. (1957). Film As Art. Berkeley, CA: University of California Press. Balázs, Béla. (1970). Theory of the Film: Character and Growth of a New Art, translated by Edith Bone. New York: Dover Publications.

Balsom, Erika. (2011). 'A Cinephilic Avant-Garde: The Films of Peter Tscherkassky, Martin Arnold, and Gustav Deutsch'. In New Austrian Film, edited by Robert von Dassanowksy and Oliver C. Speck. pp. 263-275. New York: Berghahn Books.

Barthes, Roland. (1975). The Pleasure of the Text, translated by Richard Miller. New York: Hill and Wang.

Blümlinger, Christa. (2003). 'Found Face: on Outer Space', translated by Alice Lovejoy. Senses of Cinema $28:<\mathrm{http} / / /$ sensesofcinema.com/2003/28/outer_space/>. (Accessed 20 August 2017).

Bonitzer, Pascal. (2000). 'Deframing'. In Cahiers du cinéma Vol. 4, 1973-1978: History, Ideology, Cultural Struggle, edited by David Wilson. pp. 197-203. London: Routledge.

Branigan, Edward. (2006). Projecting a Camera: Language-Games in Film Theory. New York: Routledge.

- (1992). Narrative Comprehension and Film. London: Routledge.

Cahill, James Leo. (2008). 'Anacinema: Peter Tscherkassky's Cinematic Breakdowns'. Spectator 28, no. 2: 90-101.

Coates, Paul. (2012). Screening the Face. Basingstoke: Palgrave Macmillan.

Danks, Adrian. (2006). 'The Global Art of Found Footage Cinema'. In Traditions in World Cinema, edited by Linda Badley, R. Barton Palmer, and Steven Jay Schneider. 241-253. New Brunswick: Rutgers University Press.

Deleuze, Gilles. (2005). Cinema I: The Movement Image, translated by Hugh Tomlinson and Barbara Habberjam. London: Continuum.

- and Félix Guattari. (1987). A Thousand Plateaus: Capitalism and Schizophrenia, translated by Brian Massumi. Minneapolis, MN: University of Minnesota Press. 
Doane, Mary Ann. (2003). 'The Close-Up: Scale and Detail in the Cinema'. Differences: A Journal of Feminist Cultural Studies 14, no. 3: 89-111.

Elsaesser, Thomas. (2005). 'Cinephilia, or the Uses of Disenchantment'. In Cinephilia: Movies, Love and Memory, edited by Marijke de Valck and Malte Hagener. Amsterdam: Amsterdam University Press, pp. 27-43.

— , and Malte Hagener. (2010). Film Theory: An Introduction Through the Senses. New York: Routledge.

Fowler, Catherine. (2013). 'The Clock: Gesture and Cinematic Replaying'. Framework 54, no. 2: 226-242.

Friedberg, Anne. (2006). The Virtual Window: From Alberti to Microsoft. Cambridge, MA: MIT Press.

Heath, Stephen. (1976). 'Narrative Space'. Screen 17, no. 3: 68-112.

Horwath, Alexander. (2003). 'Singing in the Rain-Supercinematography by Peter Tscherkassky', translated by Barbara Schwarz and Alexander Horwath. Senses of Cinema 28: http://sensesofcinema.com/2003/peter-tscherkassky-the-austrianavant-garde/tscherkassky/. (Accessed 20 August 2017).

Jacobs, Steven. (2011). Framing Pictures: Film and the Visual Arts. Edinburgh: Edinburgh University Press.

Lippit, Akira Mizuta. (2012). Ex-Cinema: From a Theory of Experimental Film and Video. Berkeley, CA: University of California Press.

Pierson, Michele. (2006). 'Special Effects in Martin Arnold's and Peter Tscherkassky's Cinema of Mind'. Discourse 28, no. 2/3: 28-50.

Røssaak, Eivind. (2011). 'Algorithmic Culture: Beyond the Photo/Film Divide'. In Between Stillness and Motion: Film, Photography, Algorithms, edited by Eivind Røssaak. Amsterdam: Amsterdam University Press, pp. 187-203.

Russell, Catherine. (1999). Experimental Ethnography: The Work of Art in the Age of Video. Durham NC: Duke University Press.

Silverman, Kaja. (1983). The Subject of Semiotics. Cary, NC: Oxford University Press. Sprengler, Christine. (2014). Hitchcock and Contemporary Art. New York: Palgrave Macmillan.

Tay, Sharon Lin, and Patricia R. Zimmerman. (2007). 'Throbs and Pulsations: Les LeVeque and the Digitization of Desire'. Afterimage 34, no. 4: 12-16.

Wees, William C. (2002). 'The Ambiguous Aura of Hollywood Stars in Avant-Garde Found Footage Films'. Cinema Journal 41, no. 2:3-18.

- (1993). Recycled Images: The Art and Politics of Found Footage Films. New York: Anthology Film Archives.

Žižek, Slavoj. (2001). The Fright of Real Tears: Krzysztof Kieślowski between Theory and Post-Theory. London: British Film Institute 


\section{About the Author}

Allan Cameron is a senior lecturer in Media, Film and Television at the University of Auckland. He is the author of Modular Narratives in Contemporary Cinema (Palgrave Macmillan, 2008) and co-editor, with Martine Beugnet and Arild Fetveit, of Indefinite Visions: Cinema and the Attractions of Uncertainty (Edinburgh University Press, 2017). His work has also appeared in Cinema Journal, Quarterly Review of Film and Video, Jump Cut, and The Velvet Light Trap. 
